Article

\title{
Comparison in Partition Efficiency of Protein Separation between Four Different Tubing Modifications in Spiral High-Speed Countercurrent Chromatography
}

\author{
Yoichiro Ito ${ }^{1, *}$ and Robert Clary ${ }^{2}$ \\ 1 Laboratory of Bioseparation Technology, Biochemistry and Biophysics Center, National Heart, Lung, \\ and Blood Institute, National Institutes of Health, Bethesda, MD 20892, USA \\ 2 Machine Instrumentation Design and Fabrication, National Institutes of Health, Bethesda, MD 20892, USA; \\ claryrob@od.nih.gov \\ * Correspondence: itoy2@mail.nih.gov; Tel.: +1-301-496-1210
}

Academic Editor: Alain Berthod

Received: 7 July 2016; Accepted: 11 October 2016; Published: 14 October 2016

\begin{abstract}
High-speed countercurrent chromatography with a spiral tube assembly can retain a satisfactory amount of stationary phase of polymer phase systems used for protein separation. In order to improve the partition efficiency, a simple tool was fabricated to modify the tubing shapes, and the following four different tubing modifications were made: intermittently pressed at $10 \mathrm{~mm}$ width, flat, flat-wave, and flat-twist. Partition efficiencies of the separation column made from these modified tubings were examined in protein separation with an aqueous-aqueous polymer phase system at flow rates of $1-2 \mathrm{~mL} / \mathrm{min}$ under $800 \mathrm{rpm}$. The results indicated that the column with all modified tubing improved the partition efficiency at a flow rate of $1 \mathrm{~mL} / \mathrm{min}$, but at a higher flow rate of $2 \mathrm{~mL} / \mathrm{min}$, the columns made of flattened tubing showed lowered partition efficiency, apparently due to the loss of the retained stationary phase. Among all the modified columns, the column with intermittently pressed tubing gave the best peak resolution. It may be concluded that the intermittently pressed and flat-twist improve the partition efficiency in a semi-preparative separation, while other modified tubing of flat and flat-wave configurations may be used for analytical separations with a low flow rate.
\end{abstract}

Keywords: spiral high-speed countercurrent chromatography; tubing shape modification; protein separation; polymer phase system

\section{Introduction}

Countercurrent chromatography (CCC) uses two-phase solvent systems without solid support [1-5], and it has an advantage over the conventional column chromatography for eliminating the risk of sample loss on the solid support matrix used in liquid chromatography. Since 1970, various CCC systems have been developed and their partition efficiency has been examined in terms of theoretical plate number, peak resolution, and retention of the stationary phase. Among those CCC systems, high-speed countercurrent chromatography (HSCCC) has been most widely used for the separation of natural and synthetic products [6-8]. This system uses a type-J planetary centrifuge, which rotates a coiled separation column in such a way that the column synchronously rotates about its own axis while revolving around the central axis of the centrifuge. The use of the coiled column in the rotating centrifugal force field generates an Archimedean screw effect to mix the two phases while retaining the stationary phase in the column. The separation column is fabricated by winding a long piece of polytetrafluoroethylene (PTFE) tubing coaxially around the column holder, making multiple 
layers. This multilayer coil separation column can retain a satisfactory amount of the stationary phase for moderately polar organic/aqueous two-phase solvent systems, and yields excellent peak resolution of various natural products. However, this conventional multilayer coil fails to retain a satisfactory amount of the stationary phase of polar aqueous/aqueous polymer phase systems [9], which are useful for the separation of bioactive macromolecules such as proteins and nucleic acids. In order to improve the stationary phase retention of these viscous and low interfacial tension polymer phase systems, column configuration was made in a spiral shape so that it utilizes the radially formed centrifugal force gradient to hold the heavier stationary phase in the periphery and the lighter stationary phase in the inner spiral channel to improve the retention of the stationary phase. Two types of spiral columns have been introduced; i.e., spiral disk assembly [10,11] and spiral tube assembly [11,12]. The spiral disk assembly is composed of several inert plastic disks (Kel-F, polyethylene, and polypropylene), each having four interwoven spiral channels that are connected in series with narrow channels made on the other side of the disk. It can be made various channel shapes, and can also accommodate mixing glass beads in the channel to improve the partition efficiency [13]. The spiral tube assembly is made from a plastic disk with a set of deep spiral grooves to accommodate the tubing. It has an advantage over the spiral disk assembly by eliminating the risk of leakage through the seal, but one cannot easily insert the mixers to improve the partition efficiency, as in the spiral disk assembly. Instead, the performance of the column can be improved by modifying the tube geometry to enhance the mixing and interrupt the laminar flow of the mobile phase, which would produce sample band broadening. In the past, several tubing modifications, such as cross-pressing [14] and flat-twisting [15] were manually made and tested. Although these modifications substantially improved the partition efficiency, it takes a long tedious process for column fabrication and lacks accuracy and reproducibility. Recently, Englert and Vetter have made a crimping tool to modify the tubing shape by drawing the tubing through a pair of wheels equipped with extrusions at regular intervals. They reported positive results with the modified tubing in the separation of six alkyl p-hydroxybenzoates with a multilayer coil assembly [16]. We have constructed a similar device to form various tubing shapes, such as intermittently pressed at various widths $(10 \mathrm{~mm})$, flat, flat-wave, and flat-twist [17]. In the present study, performances of these four differently-modified tubing geometries were examined in the separation of a set of stable protein samples with a spiral tube assembly by HSCCC.

\section{Materials and Methods}

\subsection{HSCCC Apparatus}

High-speed CCC separation was performed by a type-J coil planet centrifuge (P.C. Inc., Potomac, $\mathrm{MD}, \mathrm{USA}$ ). It holds a single separation column, and its counter-weight symmetrically on the rotary frame at a distance of $10 \mathrm{~cm}$ from the central axis of the apparatus. The separation column assembly was made from a spiral tube support (STS) custom-made with a laser sintering method from Nylon powder through CCBiotech, Rockville, MD, USA. It is $16 \mathrm{~cm}$ in diameter and $5 \mathrm{~cm}$ in height, and has four deep interwoven spiral grooves to accommodate a single piece of PTFE tubing of $1.6 \mathrm{~mm}$ ID (SW 14, Zeus Industrial Products, Orangeburg, SC, USA) modified into various shapes (intermittently pressed, flattened, flat-waving, and flat-twisting) by the tubing modifier. Each column has 5 spiral layers with the total capacity of 40-50 mL. For comparative studies, the same STS was filled with non-pressed tubing of the same ID, which formed 5 spiral layers with a total capacity of $60 \mathrm{~mL}$. The column was rotated at $800 \mathrm{rpm}$ with a speed controller. The effluent from the column was directly monitored with a UV detector (LKB Uvicord IIs, LKB Instruments, Bromma, Sweden) at $280 \mathrm{~nm}$, and the chromatogram was recorded with a strip-chart recorder (Millipore, Billerica, MA, USA).

\subsection{Design of the Tubing Modifier}

The basic design of the tubing modifier has been described previously (Figure 1a) [17]. It is composed of a pair of identical gears of $7.6 \mathrm{~cm}$ ( 3 inch) pitch diameters and approximately $2 \mathrm{~mm}$ thick 
with 57 spur teeth. Each gear has a $5 \mathrm{~mm}$ thick and ca. $7.5 \mathrm{~cm}$ diameter coaxial pressing wheel with three different designs; i.e., intermittently pressing (IP 10), flat, or flat-wave, as shown in Figure 1b (flat-twist configuration was made by manually twisting the flat tubing along its axis). Intermittently pressing wheels is indented every $1 \mathrm{~cm}$ to compress the tubing in $1 \mathrm{~cm}$ width at $1 \mathrm{~cm}$ intervals. The wheel for flattening tubing has no indentation with smooth surface, and the flat-waving wheel is a waving surface at $1 \mathrm{~cm}$ pitch. A long handle is attached to one of the gears to manually rotate the pair of pressing wheels, each in the opposite direction. The tubing is inserted from a side hole to reach the pressing wheels, and the rotation of the gears will compress and automatically send out the modified tubing continuously until the rotation is stopped. This pressing tool can be applied to the tubing with the wall thickness of around $0.4 \mathrm{~mm}$, and is suitable to modify the PTFE (polytetrafluoroethylene) tubing of SW20 (0.85 mm ID, analytical), SW14 (1.6 mm ID, semi-preparative) and SW 10 (2.6 mm ID, preparative).

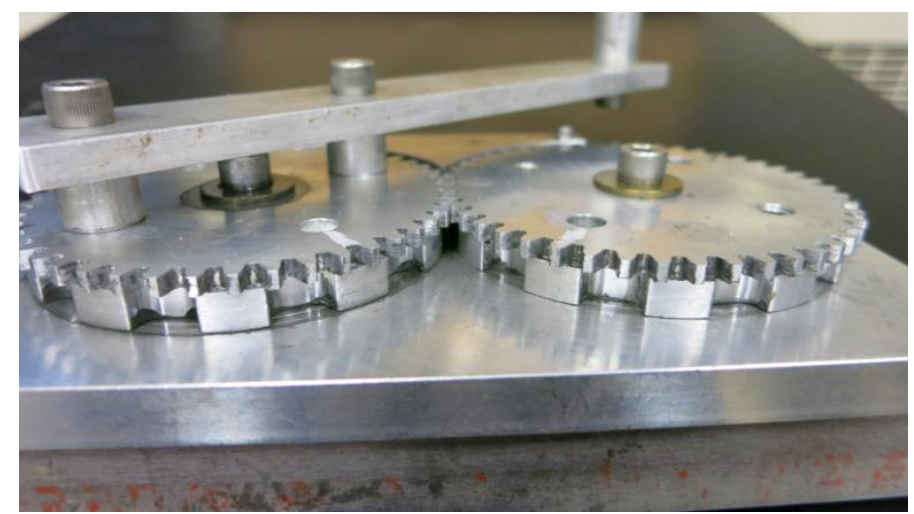

(a)

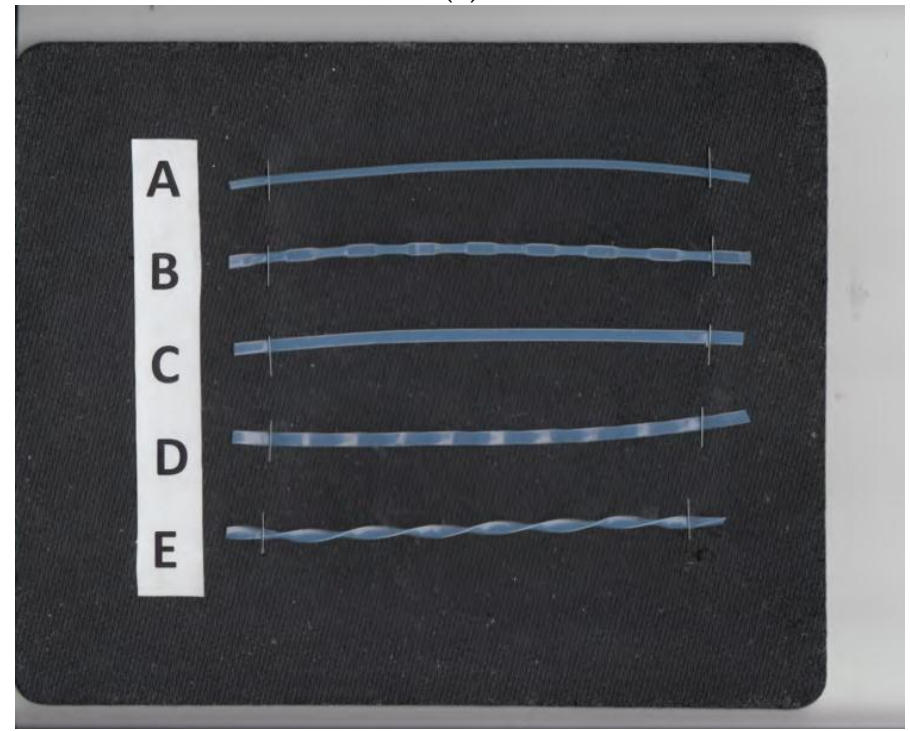

(b)

Figure 1. (a) Tubing modifier; (b) Standard and four differently modified tubings. A: standard; B: Intermittently pressing (IP) $10 \mathrm{~mm}$; C: Flat; D: Flat-wave; E: Flat-twist.

\subsection{Reagents}

Polyethylene glycol 1000 (PEG 1000), dibasic potassium phosphate, cytochrome c, myoglobin, and lysozyme were all purchased from Sigma Chemicals, St. Louis, MO, USA. Water used for preparation of the two-phase system was obtained from reverse osmosis system (Hydro Service and Supplies, Gaithersburg, MD, USA). 


\subsection{Preparation of Two-Phase Solvent System and Sample Solution}

The two-phase solvent system for protein separation was prepared by dissolving PEG 1000 and dibasic potassium phosphate, each at $12.5 \%(w / w)$, in ionized water. The solvent mixture was thoroughly equilibrated in a separatory funnel, and the two phases were separated shortly before use. Sample solution was prepared by dissolving suitable amounts of test protein mixture in the stationary upper phase used for separation.

\subsection{HSCCC Separation Procedure}

In each separation, the column was first completely filled with the upper stationary phase of the two-phase solvent system, followed by sample charge $(1 \mathrm{~mL}$ volume containing $1 \mathrm{mg}$ of cytochrome c, $10 \mathrm{mg}$ of myoglobin, and $10 \mathrm{mg}$ of lysozyme). Then, the column was rotated at $800 \mathrm{rpm}$ while the mobile phase was introduced into the internal terminal of the spiral channel at a desired flow rate $(1-2 \mathrm{~mL} / \mathrm{min})$ in a tail-to-head elution mode. The effluent from the outlet of the column was continuously monitored with a UV detector at $280 \mathrm{~nm}$. In order to improve the elution curve, the effluent was diluted with deionized water through a dialyser (Spectrum, Los Angels, CA, USA) inserted on-line near the inlet of the UV monitor at a flow rate of $1 / 10$ of the mobile phase flow. After three peaks were eluted, the rotation was stopped, and the column contents were pushed out by pressurized $\mathrm{N}_{2}$ into a graduated cylinder to determine the retention of the stationary phase. All separations were performed at room temperature.

\subsection{Analysis of HSCCC Fractions}

The partition efficiency of each separation was determined from the chromatogram in terms of theoretical plate number $(\mathrm{N})$ and peak resolution (Rs), according to the conventional formulae as follows:

$$
\begin{gathered}
\mathrm{N}=\left(4 \mathrm{t}_{\mathrm{R}} / \mathrm{W}\right)^{2} \\
\mathrm{Rs}=2\left(\mathrm{t}_{\mathrm{R} 2}-\mathrm{t}_{\mathrm{R} 1}\right) /\left(\mathrm{W}_{2}+\mathrm{W}_{1}\right)
\end{gathered}
$$

where $t_{R}$ denotes the retention time, and $W$ the peak width at base, and the subscripts indicate peak numbers. The stationary phase retention (Sf) was calculated by the volume of the retained stationary phase divided by the total column capacity and is expressed in percentage. The efficiency values obtained from the non-processed and four differently modified columns were all normalized to a $60 \mathrm{~mL}$ column volume for fair comparison (Table 1). The method of normalization is as follows:

$$
\begin{gathered}
\mathrm{N}_{\text {norm }}=\mathrm{N} \times 60 / \mathrm{V} \\
\mathrm{Rs}_{\text {norm }}=\mathrm{Rs} \times(60 / \mathrm{V})^{1 / 2}
\end{gathered}
$$

where $\mathrm{V}$ is the column capacity.

\section{Results}

Figure 2 shows a set of chromatograms obtained from the separation of three test proteins with a two-phase solvent system composed of PEG 1000 and dibasic potassium phosphate, each at $12.5 \%(w / w)$ in deionized water. All separations were performed at flow rates of 1 and $2 \mathrm{~mL} / \mathrm{min}$ under $800 \mathrm{rpm}$. Partition efficiency and retention of the stationary phase of these separations are all normalized to a $60 \mathrm{~mL}$ column capacity for fair comparison (Table 1). At $1 \mathrm{~mL} / \mathrm{min}$ flow rate, all of the modified columns show higher partition efficiency over the standard column. Among the four modified columns, IP 10 (intermittently pressed at $10 \mathrm{~mm}$ width at $10 \mathrm{~mm}$ interval) and flat-twisted tubing show the best results. At $2 \mathrm{~mL} / \mathrm{min}$ flow rate, however, the partition efficiencies of modified columns were all sharply decreased, associated with the lowered stationary phase retention, especially in flat-waved tubing, while the IP 10 column still maintained higher peak resolution $(1.17 / 1.21)$ than 
the non-pressed standard column (1.09/1.15). It is interesting to observe that the standard column and IP 10 could maintain higher retention level of the stationary phase than three other flat pressed columns which restrict the flow of the mobile phase through narrow opening of the channel.

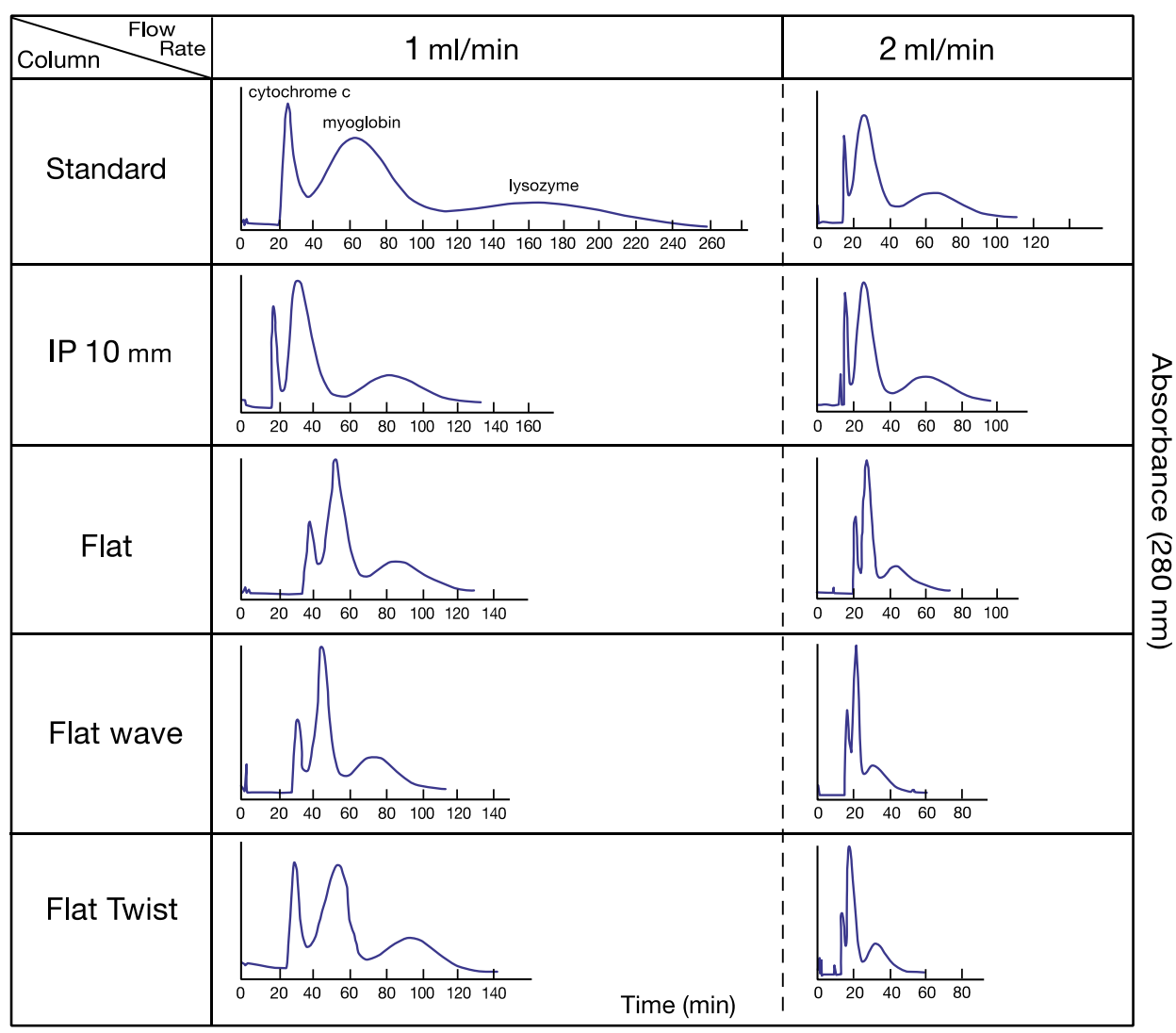

Figure 2. Set of high-speed countercurrent chromatography (HSCCC) chromatograms for protein separation using standard and four modified tubings. Experimental conditions: Apparatus was s type-J coil planet centrifuge with $10 \mathrm{~cm}$ revolution radius; the column was a spiral tube assembly with four interwoven spiral tubes containing standard and four processed tubing. The volume for each column is as follows. Standard: $60 \mathrm{~mL}$; IP 10: $52 \mathrm{~mL}$; flat: $45 \mathrm{~mL}$; flat-wave: $45 \mathrm{~mL}$; and flat-twist: $38 \mathrm{~mL}$. Solvent system: polymer phase system composed of PEG 1000 and dibasic potassium phosphate, each $12.5 \%(w / w)$ in deionized water. Sample: cytochrome c $(1 \mathrm{mg})$ (peak I), myoglobin $(10 \mathrm{mg})$ (peak II), and lysozyme $(10 \mathrm{mg}$ ) (peak III) in $1 \mathrm{~mL}$ of upper phase; flow rate: $1-2 \mathrm{~mL} / \mathrm{min}$. Mobile phase: upper phase; elution mode; tail-to-head elution; revolution speed: $800 \mathrm{rpm}$; detection: $280 \mathrm{~nm}$. Stationary phase retention: see Table 1 . IP $10 \mathrm{~mm}$ indicates intermittently pressed at $10 \mathrm{~mm}$ interval in $10 \mathrm{~mm}$ width $38 \mathrm{~mL}$.

Table 1. Partition efficiencies of standard and four modified columns by normalizing in column capacity.

\begin{tabular}{|c|c|c|c|c|c|c|}
\hline \multirow[b]{2}{*}{ Column } & \multicolumn{3}{|c|}{$1 \mathrm{~mL} / \mathrm{min}$} & \multicolumn{3}{|c|}{$2 \mathrm{~mL} / \mathrm{min}$} \\
\hline & $N_{\text {norm }}$ & $\mathbf{R s}_{\text {norm }}$ & Sf & $\mathbf{N}_{\text {norm }}$ & $\mathbf{R s}_{\text {norm }}$ & Sf \\
\hline Standard & $108 / 11 / 19$ & $1.05 / 0.90$ & $78 \%$ & $455 / 35 / 27$ & $1.09 / 1.15$ & $63 \%$ \\
\hline IP 10 mm & $460 / 46 / 39$ & $1.55 / 1.27$ & $65 \%$ & $294 / 45 / 43$ & $1.17 / 1.21$ & $56 \%$ \\
\hline Flat & $266 / 120 / 37$ & $1.21 / 0.92$ & $40 \%$ & $777 / 189 / 45$ & $0.92 / 1.02$ & $38 \%$ \\
\hline Flat-wave & $644 / 176 / 77$ & $1.36 / 1.35$ & $38 \%$ & $340 / 72 / 40$ & $0.86 / 0.75$ & $26 \%$ \\
\hline Flat-twist & $404 / 96 / 80$ & $1.82 / 1.43$ & $40 \%$ & $718 / 111 / 72$ & $0.97 / 1.02$ & $38 \%$ \\
\hline
\end{tabular}

N: Theoretical plate number (peaks 1/2/3); Rs (peaks 1 and $2 / 2$ and 3): Peak resolution; Sf; Percentage retention of the stationary phase. Note: All separations were performed at $800 \mathrm{rpm}$ and monitored UV absorbance at $280 \mathrm{~nm}$. 


\section{Discussion}

As mentioned previously, all of the modified tubing showed higher peak resolution over the non-processed tubing. The mechanism of improved partition efficiency by modification in the intermittently pressed tubing was fully discussed in our previous paper [17]. Briefly, the flattened portion of the tubing gives a larger interface and a thin layer of each phase to accelerate the mass transfer rate of the analytes. The flattened portion of the tubing will interfere with the laminar flow of the mobile phase, which would cause the sample band broadening to decrease the peak resolution. Additionally, the flattened portion gives higher flow of the mobile phase, which efficiently mixes with the stationary phase in the non-flattened portion of the column. In the present study, tubing modification is further extended to flat, flat-wave, and flat-twist. Although flat tubing has been made simply by extruding the tubing through a narrow slit as previously performed [15], the degree of the flattening depends on the opening of the slit, and the tubing tends to be stretched according to the applied force and the pulling speed; hence, it lacks accuracy and reproducibility. In contrast, positively pushing out the tubing through rotating pressing wheels used in the present study totally eliminates these problems. Among three types of flattened tubing, the flat-twist tubing gave the highest partition efficiency, as shown in Table 1. The partition efficiency of the columns made of flattened and flat-waved tubing will be increased by decreasing the flow rate and/or increasing the revolution speed, but with an increased separation time. These tubings can be accommodated in the STS with much narrower channels of a sharper spiral pitch and used for analytical separations at a low flow rate of the mobile phase.

Author Contributions: Robert Clary made the tubing modification tool at the NIH machine shop. Yoichiro Ito used it to carry out experiments and wrote the manuscript.

Conflicts of Interest: The authors declare there is no conflict of interest.

\section{References}

1. Ito, Y.; Bowman, R.L. Countercurrent chromatography: Liquid-liquid partition chromatography without solid support. Science 1970, 167, 281-283. [CrossRef] [PubMed]

2. Mandava, N.B.; Ito, Y. Countercurrent Chromatography: Theory and Practice; Marcel Dekker: New York, NY, USA, 1988.

3. Conway, W.D. Countercurrent Chromatography: Apparatus, Theory \& Applications; VCH Publishers, Inc.: New York, NY, USA, 1990.

4. Berthod, A. Countercurrent Chromatography: The Support-Free Liquid Stationary Phase; Wilson \& Wilsons, Elsevier: New York, NY, USA, 2002.

5. Menet, J.-M.; Thiébaut, D. Countercurrent Chromatography, Chromatographic Science Series; Marcel Dekker: New York, NY, USA, 1999; Volume 82.

6. Ito, Y.; Conway, W.D. (Eds.) High-Speed Countercurrent Chromatography; Wiley-Interscience: New York, NY, USA, 1996.

7. Ito, Y. High-speed countercurrent chromatography. Crit. Rev. Anal. Chem. 1986, 17, 65-143. [CrossRef]

8. Ito, Y. High-speed countercurrent chromatography. Nature 1987, 326, 419-420. [CrossRef] [PubMed]

9. Albertsson, P.Å. Partition of Cell Particles and Macromolecules; Wiley-Interscience, John Wiley \& Sons: New York, NY, USA, 1986.

10. Ito, Y.; Yang, F.-Q.; Fitze, P.E.; Powell, J.; Ide, D. Improved spiral disk assembly for high-speed countercurrent chromatography. J. Chromatogr. A 2003, 1017, 71-81. [CrossRef] [PubMed]

11. Ito, Y. Spiral column design for separation of proteins by high-speed countercurrent chromatography. Chem. Eng. Process. 2010, 49, 782-792. [CrossRef] [PubMed]

12. Ito, Y.; Clary, R.; Powell, J.; Knight, M.; Finn, T.M. Spiral tube support for high-speed countercurrent chromatography. J. Liq. Chromatogr. Relat. Technol. 2008, 31, 1346-1357. [CrossRef] [PubMed]

13. Ito, Y.; Clary, R.; Sharpnack, F.; Metger, H.; Powell, J. Mixer-settler counter-current chromatography with multiple spiral disk assembly. J. Chromatogr. A 2007, 1172, 151-157. [CrossRef] [PubMed] 
14. Ito, Y.; Clary, R.; Powell, J.; Knight, M.; Finn, T.M. Spiral tube assembly for high-speed countercurrent chromatography: Choice of elution modes for four typical two-phase solvent systems. J. Liq. Chromatogr. Relat. Technol. 2009, 32, 2013-2029. [CrossRef]

15. Tong, S.-Q.; Ito, Y.; Ma, Y. Enantioseparation of DL-tryptophan by spiral tube assembly counter-current chromatography and evaluation of mass transfer rate for enantiomers. J. Chromatogr. A 2014, 374, 77-84. [CrossRef] [PubMed]

16. Englert, M.; Vetter, W. Tubing modifications for countercurrent chromatography (CCC): Stationary phase retention and separation efficiency. Anal. Chim. Acta 2015, 884, 114-123. [CrossRef] [PubMed]

17. Ito, Y.; Ma, X.-F.; Clary, R. A simple tool for tubing modification to improve the spiral high-speed counter-current chromatography. Curr. Chromatogr. 2016, 3, 129-135. [CrossRef]

(C) 2016 by the authors; licensee MDPI, Basel, Switzerland. This article is an open access article distributed under the terms and conditions of the Creative Commons Attribution (CC-BY) license (http://creativecommons.org/licenses/by/4.0/). 